\title{
Problems Discussion and Strategy Research on Cross-culture Foreign Language Teaching over National Universities
}

\author{
Lei Ma \\ Xinjiang Institute of Light Industry Technology, Urumqi, 830000, China
}

\begin{abstract}
Keyword: Cross-cultural foreign language teaching. Foreign language teaching in universities. Cross-cultural foreign language communication teaching. Culture teaching
\end{abstract}

\begin{abstract}
The cross-culture foreign language teaching is the product of the cross-cultural communication of contemporary foreign language teaching in university, while it has been in developing as the trend of globalization economy. Research of cross-cultural teaching in universities has commenced very early, however, problems are still found in the practical teaching. Therefore, the improvement on cross-cultural foreign language teaching should combine the reality of universities foreign language teaching with the success of foreign countries teaching foreign languages, and making the teaching methods and goals rationally for the cross-cultural foreign language teaching. Meanwhile, according to the content, perfect the cross-cultural foreign language teaching material and reserve the excellent resources of foreign language teaching. This paper will develop the approaches that improve the cross-cultural foreign language teaching in universities, combined with the current situation and existing problems of cross-cultural foreign language teaching in universities.
\end{abstract}

\section{Introduction}

Integration trend with the global economy has enhanced the relationship over countries. Under this trend, our country has increased global communication and cooperation, and because of resent situation, the cross-cultural foreign language teaching has faced up to greater challenges. In the rest of this paper, the measurements to improve cross-cultural foreign language teaching will be discussed according to present situation, combined with the significance, situation and exiting problems of cross-cultural foreign language teaching.

\section{Significance of Increasing Cross-cultural Foreign Language Teaching in Universities' Foreign Language Teaching}

\section{Assist students in understanding the cultural background of the foreign language they are learning}

The origin of language is influenced by the local cultural background. The variety of languages comes from the different cultures, which is the proof that culture and language is an indivisible entirety according to the researchers at present times. Language teaching is one of the demonstrations of culture teaching. In practical teaching, increasing cultural teaching is good for students to understand the importance of language based on their own culture background, and to improve their understanding and perceive level of language. Take the English study in universities as the example. English is a subject of language, while in practical teaching the culture background of English-speaking countries must be brought in, and students will learn the knowledge of language under this culture background. Students have to understand the culture background of English-speaking countries during their learning in English. As they have understood the difference in culture between their mother country and English-speaking countries, their application and master of English will be improved and their foundation of English will be consolidated. Therefore, to embed the cross-culture teaching in foreign language teaching will make use of the culture background of foreign language to instruct the students in learning this foreign language and help them to improve their comprehensive application ability of the foreign language.

Help to improve the teaching results 
Language separated from the culture is just obscure pronunciation, while under the background of culture language will be attached with meanings. Taking English learning as the example again, in foreign language teaching in universities, English teaching is performed combining the English texts and the history and culture background of English-speaking countries. This teaching process is actually the process of cross-cultural English communication teaching. Additionally, Education Department has realized the deep understanding of culture and history of learned foreign language in the teaching of foreign language in universities is very helpful in learning that foreign language; the corresponding application of language will be improved and the global sense will be enhanced as well with the understanding of other cultures. Therefore, students in learning language and culture will benefit from the cross-culture language teaching; meanwhile the teaching results of universities' foreign language teaching will be improved as well.

\section{Current Situation and Existing Problems of Cross-cultural Foreign Language Teaching in Universities}

\section{Current situation of cross-cultural foreign language teaching in universities}

The cross-cultural foreign language teaching has experienced a long time (about 60 years), and it obtains faster development under current situation. Therefore, the issue, that how to improve the foreign language communication ability over the culture of students has attracted the attentions of relevant scholars. Domestic scholars have reached the agreement that the foreign language teaching must combine with the culture teaching. With the popularization of this method, many teaching materials and academic papers have been published in the area of universities' foreign language teaching; meanwhile, the syllabus and design of curriculum are focus on this method as well. However, there exist some problems in practice, which result in the output not satisfactory as the expectation.

\section{Deficiency existing in cross-cultural foreign language teaching in universities}

Language teaching and cultural teaching is not unified due to the difference on teaching idea

Culture teaching is separated from language teaching factitiously during the teaching of cross-culture foreign language teaching in universities. In the teaching of foreign language, the language ability has become the concentration while the culture teaching is ignored. Lecturers are engaged in the teaching language knowledge, without the systematic integration of culture and language teaching. As a result, the culture teaching has not played an important role in foreign language teaching. Additionally, the traditional exam-oriented education thought has affected the foreign language teaching a lot. It is widely accepted by university teachers that the English level of students can be represented via the foreign language grade examinations (CET-4, CET-6, TEM-4, TEM-8, interpretation tests, etc.). Consequently, the proportion of language teaching has been increased; the knowledge from texts is poured to students; the explanation on language knowledge, such as words and grammar, and asking the students to recite of language knowledge becomes the concentration of teaching. Hence, this kind of teaching approach will influence the study focus of students; they will concentrate more on language knowledge study while neglect the culture study. Additionally, as a result of this teaching thought, the language teaching has been separated from the culture teaching, so that the cross-culture communication ability becomes weaker because students know little about culture background of other countries. The lack of culture background understanding, during their communication, students know little about other countries or consider from our own culture, so that the difficulty in communication is inevitable.

\section{Lack of culture teaching in the content of cross-cultural foreign language teaching in universities}

Contemporarily, the foreign language knowledge elements (vocabulary, grammar and syntax) are the main components of foreign language teaching in universities. This design of teaching content focuses more on the teaching of exams, knowledge and theories, while ignores the cultivation of comprehensive quality, learning methods and communication skills. Under current design of teaching content, the students are required to recite vocabulary, grammar and sentence patterns in 
teaching which has stereotyped the foreign language teaching totally, and the individual characteristic teaching is ignored. Under this mode, students are lack of the cultivation on cross-culture communication skills, resulting in the lack of comprehensive ability in language application.

\section{Lack of satisfactory professional foreign language teaching materials}

Foreign language teaching materials are the direct representative of the content of language teaching, and it presents the content and objective of culture and language teaching. Some excellent university foreign language teaching materials are compiled successively and the original edition lf foreign language teaching materials are brought in presently. Taking English as an example, the excellent materials such as New Horizons College English and College English are not only focus on the language knowledge, but also the demonstrate different levels of European and American culture. These profound materials have broken through the limits of traditional materials and increased the culture teaching, which has promoted the general English learning in university. However, the compiling and reform of professional English major is in great lag, for English majors in universities are still using the material compiled in "the ninth Five-Year plan". Apparently, these materials are no longer satisfied the requirements in cultivating English professionals. Consequently, the laggard materials have affected the teaching results to some extent. Teachers cannot transfer the relative progressive knowledge to students via outdated materials; they have to transfer the unsystematic knowledge collected by the teachers. Culture teaching is lack of effective carrier and basement with outdated materials, which hinder the cross-culture teaching implementation of professional English in universities.

\section{Lack of profound teaching staff of foreign languages in universities}

Although the foreign language teaching theories are in continuous reformation, and teachers have realized the significance of culture teaching, as the lack of profound teaching staff of foreign languages, the cross-culture foreign language teaching is difficult to realize. On one hand, teachers know the significance of culture teaching, but the culture teaching isn't integrated into practical teaching. Teachers follow the traditional teaching method, focusing on the teaching of language. English study of students is under the traditions, from which the cross-culture communication abilities cannot be cultivated. On the other hand, teachers are far away from the culture of the language they have taught, namely lack of the experience staying that country. Without deep understanding on the difference of foreign cultures and domestic culture, teachers have to learn by themselves via other approaches (Internet, Multimedia and books). Therefore, according to the two points mentioned above, the teaching team of foreign language must be strengthened urgently.

\section{Approach of Enhancing Cross-cultural Foreign Language Teaching in Universities}

\section{Prepare correct teaching goals and enhance the cross-cultural foreign language teaching}

Cross-culture teaching is firstly demonstrated by American scholars, and the issue that how culture teaching is realized in foreign language teaching has been stated, namely how to implement culture teaching in different stages of foreign language teaching. The correct goal of foreign language teaching should reach the results that people from different culture and speaking in different languages can communicate fluently, and the communication skills of students are improved. According to current requirements of English professionals, the foreign language teaching in universities should enhance the application and master of pronunciation, and the ability of cross-culture communication. Therefore, the teaching of foreign language must take the culture and language teaching as a whole and reflect the teaching thought via syllabus, material, teaching and exams, so that the English cross-culture teaching will be strengthened.

\section{Reinforce the construction}

Foreign language teachers in universities should transfer their teaching thoughts firstly to cover the deficiencies in traditional foreign language teaching. The teachers must firstly realize that language learning is learning the communication tool, while its fundamental purpose is communication. Meanwhile, teachers must realize the necessity of culture teaching in foreign 
language teaching, so that they can penetrate the culture teaching into routine teaching. As most teachers don't have the background living overseas, and as they don't have the systematic understanding on the difference between foreign and domestic culture, universities can hold the training on teachers with the cross-culture communication, helping them to understand the foreign cultures gradually. Meanwhile, universities can invite the teachers who have the living and learning experience overseas to train the teachers who don't have these experiences, to deepen their understanding of foreign cultures. Additionally, universities with sufficient resources can send teachers abroad for learning, observing and communication, to enhance their cross-culture teaching abilities. Finally, the popularity of significance and definitions of cross-culture teaching must be continued, to incept the idea of cross-culture teaching in the mind of teachers.

\section{Perfect teaching content to cultivate the cross-culture communication of students}

Master of language and improvement of language application will help students to understand the culture, which improves the culture idea of students. Therefore, it is helpful in foreign language teaching to improve the culture idea of students in understanding the background, history and progression of culture, and then the culture teaching is realized. To compare domestic culture with foreign cultures, students will understand the other cultures better. For example, increase the course of British and American Literature and the course of British and American Literature Introduction in curriculum, students will have better understanding of foreign culture based on domestic culture. Therefore, the cross-culture foreign language teaching in universities can't be separated from the teaching of humanities, which is a comprehensive theory involving in philosophy, linguistics and psychology.

\section{Reinforce cross-culture teaching via multiple methods}

Firstly, vocabulary is the basic composition of language, which is the content of both language and culture teaching. Therefore, the vocabulary teaching requires not only the explanation of the meaning and use of vocabulary, but also the culture meaning behind the vocabulary. In this case, students will obtain the usage of vocabulary and the understanding of culture. Via the comparison of the vocabulary of Chinese and other languages, students will have more flexible application and the enhanced communication ability cross-culturally. Secondly, as the limitation of environment, the teaching of foreign language is impossible to create the study under the background of foreign culture. To offset the limitation, the culture teaching environment can be created in teaching, introducing students communicating with the objective language in specific communication occasions, so that to improve their application cross-culturally. Meanwhile, to increase the part of role play, such as asking students to communication in playing different roles, students will master the social etiquettes for different occasions, increasing their communication abilities. Lastly, in professional English teaching, the more rational material or the foreign original teaching material are required. The deep culture meaning of materials will be concluded to enhance the cultural study of students between the lines. Meanwhile, combine the culture teaching and language teaching via the materials. Additionally, it will improve the cross-culture teaching level to invite the foreign scholars to give speeches in universities.

\section{Conclusion}

As the teachers have realized the significance of cross-culture teaching, we have obtained some outcomes in cross-culture teaching. According to the current problems, the teachers should improve the practical work and accumulate experience, to improve the teaching ability of cross-culture, so that cultivate professionals with consolidated foundation and skillful cross-culture communication abilities, and provide the society with professional application smarts of comprehensive qualities.

\section{References}

[1] $\mathrm{Xu}$ Wenting: the Requirements of Cross-culture Foreign Language Teaching to University Teachers, Nanguo Today (Theory Innovation Edition), 2009(10) 
[2] Wang Xiuqin: Research on Self-motivated Learning and Cross-culture Foreign Language Teaching, Xinxiang College Journal (Society and Science Edition), 2010(2)

[3] He Muchun: Analysis on Cross-culture Foreign Language Teaching in Universities, Exploration of Education, 2010(12)

[4] Xia Xiaohua: Discussion and Analysis on Cross-culture Foreign Language Teaching in Vocational Colleges, Social Science in Jiangsu, 2012(S1)

[5] Xu Huifang: Development of Cross-culture Communication Courses of Universities, Master, 2010(19)

[6] Dang Yonghui: Research on Cross-culture Foreign Language Teaching in English Teaching, Time Education, 2012(13)

[7] Han Yuanyuan: Popular Approaches in Cross-culture Foreign Language Teaching, Academy (Education Research), 2012(19) 